\title{
Achegamento aos grupos de galegos en Madrid durante os primeiros trinta anos do século XX: a Mocedade Céltiga*
}

\author{
An Approach to the Galician Groups in Madrid during the First Thirty \\ Years of the 20th Century: The so-called "Mocedade Céltiga"
}

\author{
Ana ACUÑa \\ Universidade de Vigo \\ Departamento de Filoloxía Galega e Latina \\ ganime@uvigo.es \\ [recibido 13/10/2014, aceptado 26/01/2015]
}

\section{RESUMO}

Nesta exposición profundarase nun grupo de galegos en Madrid que, baixo diferentes nomes (Xuventude Céltiga, Irmandade Céltiga de Madrid, Mocedade Céltiga, Delegación da Irmandade Nazonalista Galega) e arredor de Fermín Penzol, se desenvolveu entre 1919 e 1926.

Palabras Chave: Grupos de galegos en Madrid, Fermín Penzol, Mocedade Céltiga.

\section{RESUMEN}

En esta exposición se profundizará en un grupo de gallegos en Madrid que, bajo diferentes nombres (Xuventude Céltiga, Irmandade Céltiga de Madrid, Mocedade Céltiga, Delegación da Irmandade Nazonalista Galega) y alrededor de Fermín Penzol, se desarrolló entre 1919 y 1926.

Palabras Clave: Grupos de gallegos en Madrid, Fermín Penzol, Mocedade Céltiga.

\section{ABSTRACT}

This study will be centered on a group of Galicians formed around the figure of Fermín Penzol. This group, which adopted different names (Xuventude Céltiga, Irmandade Céltiga de Madrid, Mocedade Céltiga, Delegación da Irmandade Nazonalista Galega), existed from 1919 to 1926.

KEY WORDS: Group of Galicians in Madrid, Fermín Penzol, Mocedade Céltiga.

ACUÑA, A. (2015): “Achegamento aos grupos de galegos en Madrid durante os primeiros trinta anos do século XX: a Mocedade Céltiga”, Madrygal (Madr.), 18, Núm. Especial: 399-409.

SUMARIO: 1. Introdución. 2. Contexto. 3. Fermín Penzol e o nacemento do nacionalismo galego de preguerra en Madrid. 4. Rexistros públicos e oculto. 5. Espazos e contraespazos de sociabilidade. 6. Conclusións. 7. Referencias bibliográficas.

\footnotetext{
* A elaboración deste texto foi levada a cabo no marco do proxecto de investigación "Ex-sistere. La movilidad de las mujeres en las literaturas gallega e irlandesa contemporánea", dirixido por Manuela Palacios e financiado polo Ministerio de Economía y Competitividad e FEDER (FFI 2012-35872).
} 


\section{INTRODUCIÓN}

En estudos anteriores sobre a literatura galega en Madrid (Acuña 2009 e 2014) resaltamos a figura sobranceira de Fermín Fernández Penzol nos primeiros anos do século XX pola súa importancia non só cultural senón tamén política.

Naquela altura o noso achegamento a este período non puido ser maior por non formar parte do tempo por nós acoutado (1950-2000). Con todo, a nosa curiosidade non decaeu e aproveitamos estas xornadas para volver aos arquivos e procurar documentos ${ }^{1}$ que agora presentamos.

Confrontando os nosos datos cos de Justo Beramendi (2007), a cronoloxía e os grupos de galegos durante os trinta primeiros anos do século XX estarían estreitamente relacionados con dous nomes:

- Aurelio Ribalta, quen, baixo o nome xeral de grupo de Estudios Gallegos (Beramendi 2007), lideraría distintos momentos: Estudios Gallegos (1915), Reunión d'Estudios Gallegos (1916) e o Secretariado de Galicia en Madrid (1918) ${ }^{2}$.

- Fermín Penzol, quen, baixo o denominador común de Mocedade Céltiga, impulsaría diferentes agrupacións: Xuventude Céltiga (c. 1919-1920), Irmandade Céltiga en Madrid (c. 1921-1922), Delegación da Irmandade Nazonalista Galega, ING (c. 1922-1923), Mocedade Céltiga (c. 1924-1925), intento de grupo secreto ("independencista" e "segredo") (c. 1926) e Acción Galega Radical Autonomista, AGRA (c. 1930).

Se nos primeiros momentos (1915-1918) foi fundamental a presenza do escritor Aurelio Ribalta, nos seguintes (1919-1926) tivo importancia capital a figura do bibliófilo Fermín
Fernández Penzol. A nós interésanos o movemento galeguista arredor desta última personalidade a causa da disparidade de denominacións (ás veces, simplificación) e de asignación temporal. A proliferación de nomes puido obedecer aos distintos momentos vividos polo nacionalismo de anteguerra e que J. Beramendi resumiu en: transición do rexionalismo ao nacionalismo, nacionalismo unido (Irmandades da Fala), nacionalismo dividido (Irmandade da Fala vs Irmandade Nazonalista Galega) e aparición de organizacións pequenas e efémeras previas á República.

Antes de entrar na complexidade da análise diacrónica (case arqueolóxica) e co obxecto de intentar aclarar os diferentes estratos, consideramos necesario un breve repaso histórico polo contexto dos galegos en Madrid durante as primeiras décadas do século pasado para despois centrármonos nas etapas protagonizada por F. Penzol.

Queremos advertir de que non pretendemos presentar conclusións definitivas, pois os arquivos, como os rabos das cereixas, van arrastrando uns a outros. Por tanto, non consideramos acabada esta investigación, a pesar da nosa revisión do arquivo Penzol ${ }^{3}$, previamente realizada por Ramón Piñeiro e publicada -en parte- no ano 1981 con motivo dunha homenaxe.

Se nese ano (1981) Ramón Piñeiro publicaba 28 cartas entre Penzol e 16 remitentes (persoas e entidades) e establecía unha historia da Mocedade Céltiga a partir dunha desas epístolas; para esta ocasión, nós lemos cartas e postais intercambiadas con, aproximadamente, 40 remitentes (persoas e entidades) ${ }^{4}$, ás que lles sumamos a interesesantísima correspondencia mantida con Víctor Casas (e da que non daba conta Ramón Piñeiro).

\footnotetext{
${ }^{1}$ Arquivos localizados na Fundación Fermín Penzol (fondo Ramón Piñeiro e Fermín Penzol) e na Real Academia Galega (fondo Ramón Villar Ponte).

${ }^{2}$ Segundo Beramendi (2007: 433), o apelativo Secretariado de Galicia en Madrid "pervivirá con moi escasa actividade ata a época da República".

${ }^{3}$ Sen saber unha do outro, a nosa lectura foi acompañada pola do investigador Xurxo Martínez a quen lle agradecemos a xenerosa achega de documentación e intercambio de opinións.
} 


\section{CONTEXTO}

Non podemos esquecer algúns datos que marcan o galeguismo político nos comezos do século XX e que están presentes no epistolario de F. Penzol. De todos eles, destacamos dous: o triunfo parcial do nacionalismo irlandés fronte ao Imperio Británico e as secuelas da revolución bolxevique en toda Europa. Un e outro aparecerán unidos, como veremos, á hora de abordar os rexistros públicos e ocultos das últimas agrupacións de galegos en Madrid que se enumeraron no apartado anterior como vinculadas a Fermín Penzol.

Tampouco podemos obviar que nos comezos do século se producen unha serie de acontecementos políticos internos e relevantes: crise da monarquía afonsina (Afonso XIII), auxe dos movementos obreiros e campesiños moi combativos, fracturas ideolóxicas e políticas, demandas de autonomía dos nacionalismos catalán e vasco, conflitos en Marrocos, golpe de estado de Miguel Primo de Rivera e inestabilidade organizativa do nacionalismo entre 1916 e 1924.

\section{FERMÍN PENZOL E O NACEMEN- TO DO NACIONALISMO GALEGO DE PREGUERRA EN MADRID}

Á hora de tratar o nacemento do nacionalismo galego, debemos sinalar as distintas fases que padeceu e das que Madrid non se librou. Referímonos a elas na introdución pero convén recordalas neste momento: transición, nacionalismo unido (Irmandades da Fala), nacionalismo dividido (Irmandade da Fala vs. Irmandade Nazonalista Galega) e organizacións efémeras.
A través do epistolario de Fermín Penzol, publicado -en parte- por Ramón Piñeiro con motivo da homenaxe que lle dedicou a revista Grial, sabemos destes movementos en Galicia e do seu ecoar en Madrid. O propio Penzol fai unha historia destes movementos asociativos nunha carta enviada a Xavier Pardo e que Ramón Piñeiro reelaborou nun artigo da citada revista. Seguindo, xa que logo, a historia elaborada por F. Penzol para X. Pardo, podemos resumir como segue a historia das agrupacións nacionalistas trala desaparición (total ou parcial) daquelas protagonizadas por Aurelio Ribalta:

- Xuventude Céltiga, c. 1919-1920

- Irmandade Céltiga en Madrid, c. 1921-1922

- Delegación da Irmandade Nazonalista Galega, c. 1922-1923

- Mocedade Céltiga, c. 1924-1925

- Intento de grupos secretos ("independencista" e "segredo"), c. 1926

Fronte á nosa separación en catro momentos, Ramón Piñeiro (1981a) recoñece só tres etapas ao non separar a Irmandade Céltiga da Delegación da Irmandade Nazonalista Galega. Por outra parte, debemos advertir que, tralo primeiro momento, o nome usado maioritariamente por Penzol será o de Mocedade Céltiga ${ }^{5}$, tanto na etapa das Irmandades da Fala, como na etapa da Irmandade Nazonalista Galega.

Da primeira etapa (Xuventude Céltiga), na que Penzol non ocuparía ningún cargo, temos noticia nos epistolarios mantidos con Víctor Casas (08/06/1920) e Xavier Pardo (02/07/1926). O primeiro pídelle a Penzol explicacións e suscritores para A Nosa Terra:

${ }^{4}$ F. Bouza Brey, V. Risco, M. Cortón, R. Cabanillas, E. González López, J. Ma de la Fuente Bermúdez, Embaixada Británica, I. Rodríguez, Irmandades da Fala, R. Villar Ponte, A. Villar Ponte, A. Ramos, A. Romero Cerdeiriña, P. Galindo, L. González Salgado, A. López Trasancos, D. López Valcárcel, F. Martínez, S. Mosteiro Pena, Ben-Cho-Shey, X. Pardo, M. P. Piñeiro, X. Carracedo, X. Filgueira, L Cortiñas, L. Cortón, X. Peña, Mocedade do CEG, Galicia, El Pueblo Gallego, R. Isla Couto, F. Gómez, F. Lamas, Ateneo de Vigo, nacionalistas de Ourense, Comité Arredista na Habana Xuntanza Nazonalista Galega...

${ }^{5}$ Escríbelle Penzol a Pardo “un pouco de historia encol da "Mocedade Celtiga” de Madrid” (02/07/1926). 
En varias cartas suas falame de un grupo de rapaces nazonalistas que nos non sabemos quenes son, nos coidabamos que en Madrid non habia mais nazonalistas que vosté, Ignacio Rodríguez e Manoel de la Peña e Correa Calderón (...) Así é que si hay mais digame os nomes e procure facel-os pol-o menos suscritores do boletín.

Na carta mencionada ${ }^{6}$ a Xavier Pardo, Penzol revélalle, ademais da orixe do grupo, os encontros e desencontros coa Casa de Galicia:

Modesto Pérez Piñeiro de Ourense recibiu do Risco a pouco de se ter rematado a Asambreia Nazonalista de Compostela [1919], o encarrego d'orgaizar un grupo en Madrid. (...) Dito rapaz na compaña de Francisco Fariña -un arribista que habia sido segredario da antiga "Casa de Galicia" e que queria valendose de nós voltar a selo- e do Correa Calderon, o organizou co nome de "Xuventude Celtiga".

Ao pouco tempo, debeu solicitarse o ingreso na Irmandade da Fala, porque Víctor Casas -membro da Irmandade da Fala da Coruña- 1le indica o procedemento a Penzol (20/3/1921):

Cando esté constituida dirixanse a ista Irmandade oficialmente solicitando o ingreso no direitorio como a si o veñen facendo todal-as demais que se orgaizan (...) Hoxe mándolles os regramentos que me piden. As fouces ${ }^{7}$ non llas poido mandar porque non as hai.

Desta segunda etapa atopamos na Fundación Penzol cartas cuxa cabeceira contén o nome
Irmandade Céltiga en Madrid. Á súa vez Xosé Luís Axeitos recuperou un documento (09/05/1921) do arquivo da Real Academia Galega no que aparecen relacionados os nomes da directiva do grupo e, entre eles, o do noso protagonista -como primeiro conselleiro ${ }^{8}$ xunto con outros estudantes e traballadores.

Así explica Fermín Penzol o 02/07/1926 os cambios operados nesta etapa:

Un fato de irmaos ${ }^{9}$ dirixidos pol-o pra nós inesquecível e ja finado irmao Ignacio Rodríguez Varela (q.e.p.d), n-unha xuntanza fixemos trocal-o nome de Xuventude pol-o de Mocedade conquerindo tamén que o Fariña e mail-o Correa non voltaran figurar a nosa veira por non coidar no seu nazonalismo. Asina llo comunicamos ao Direitoiro Nazonalista, composto por Risco, Vilar Ponte e Bonet Fontenla. Despois e pol-o mesmo prescindimos do Piñeiro, e mais tarde d'outro rapaz chamado Manuel Fuentes [Canal] de Verin.

Ao final da carta, Penzol enumera os cargos e os seus ocupantes ${ }^{10}$ e non se corresponden exactamente cos expostos no documento enviado a $R$. Villar Ponte e localizado na $\mathrm{RAG}^{11}$.

Curiosamente, e como vimos advertindo, na carta/historia de F. Penzol o nome utilizado para o grupo é Mocedade, aínda que noutras cartas (1921 e 1922) se alude a Irmandade Céltiga en Madrid. Quizais a preferencia pola denominación Mocedade Céltiga ${ }^{12}$ se deba á opinión de Víctor Casas. Este, nunha carta do

${ }^{6}$ Carta editada parcialmente por Ramón Piñeiro en 1981.

${ }^{7} \mathrm{O}$ logotipo da Irmandade Céltiga de Madrid ten unha fouce como figura central, entre outros elementos.

${ }^{8}$ Estes son os nomes e os seus cargos: Fermín Penzol como $1^{\circ}$ conselleiro, Salvador Mosteiro como $2^{\circ}$ conselleiro, Modesto Piñeiro como segredario, Joaquín Peña como vice-segredario, Lois Cortón do Arroyo como tesoureiro contador, Domingo L. Valcárcel como vocal, Xesús Carracedo como vocal, Ramón Rodríguez como vocal e Lois Cortiñas como vocal. Segundo unha carta de V. Casas, Penzol tivo que asumir ese cargo ao marchar outro compañeiro.

${ }^{9}$ Riscardo "estudantes".

10 “Conselleiro 1": Penzol; Conselleiro 2o: Mosteiro da Pena; Segredario: Xaquín Pena; Vicesegredario: Domingo Valcarcel; Bibliotecario: Ramón Rodríguez Somoza; Tesoureiro: Cortón do Arroyo; Vocaes Ignacio R. Varela, Xesus Carracedo e Lois Cortiñas".

${ }^{11}$ No documento enviado a X. Pardo (Fundación Penzol) aparece o cargo de bibliotecario que non se rexistra no enviado a R. Villar Ponte (RAG).

${ }^{12}$ Emilio González López (1987), pola súa parte, prefire a denominación xeral de "Celta" para referirse á organización de estudantes galegos. 
20/03/1921, indica: "Unha advertenza: Non deben poñerlle o nome «Xuventude» sinón «Mocedade». Fixense que «Xuventude» é castelanismo -joven en castelán é mozo en galego. Vexan de correxir esto".

Da terceira etapa (1922-1923), F. Penzol indícanos na carta/historia (02/07/1926) que vimos citando as circunstancias que fixeron mudar de nome, agora Delegación da Irmandade Nazonalista Galega:

Despois da Asambreia de Monforte trocamonos en Delegación da ING e fundamos en Betanzos o boletin Rexurdimento -orgao das Mariñas- pasando, a petición de Risco, a sere orgao da ING e fumos -seguramente os únicosque decote cumprimol-os acordos de Monforte.

Trala chegada da "besta moura" (en palabras de Penzol e que nós entendemos como a ditadura de Primo de Rivera) e dos problemas detectados no nacionalismo en Galicia ${ }^{13}$, iníciase unha cuarta etapa (c. 1924-1925) baixo o nome, agora si, de Mocedade Céltiga para "conquerir houbera na terra unha orgaización nazonalista".

Obsérvese como volve partir de Madrid a necesidade de reorganizar o nacionalismo (Beramendi 2007: 428). A proposta de Madrid será unha das tres ás que poderán optar os nacionalistas (xunto coa do grupo de Viveiro e a da Irmandade da Fala) e que pretende, segundo a carta de Penzol a Leuter Salgado (23/02/1925), "orgaizar unha mocedade independentista, que non teña necesidade de gefes senon de mestres, que traballa pra se capacitar e poder pôr o dia de mañán o seu grao de area na creación d'unha cultura arredistamente galega".

Con todo, os mozos de Madrid non encontraron en Galicia o eco desexado:

Cousas de machacar en ferro frío e de aguantar fallas de educación - pois nin por cortesia eramos respostados as nosas cartas-acordamos disolver a MC deixando aos seus membros en compreta liberdade d'aición e dando remate aos traballos que tiñamos feito.

(...) asina dous rapaces d'unha grande inquietude e d'un fondo valimento inteleitual, ingresaron un no Partido Comunista e outro na organización revolucionaria que na "Escuela Nueva" dirixen Jiménez de Asúa e o $\mathrm{D}^{\text {or }} \mathrm{Ma}$ rañón”.

A quinta etapa estará marcada polo illamento e esfarelamento do pouco que existe e o intento de crear grupos secretos de tipo masónico ou relixioso. Filgueira Valverde responde á desesperanza dos galegos en Madrid (23/11/1925):

vostedes teñen perdidal-as esperanzas de sere correspondidos por nos no seu degaro de dar unidade o esforzo nazonalista faguendo centro de aición esta vella vila de Compostela (...).

(...) procedimos a crear, con caraiter segredo e clandestino, o grupo nazonalista de Santiago. Tendo xa disposto agora iste orgaismo fundado por nos a base de estudantes, podemos corresponder na medida das nosas forzas os seus degaros e astra si se quer sere elemento central da sua realizaron.

Ao ano seguinte, Penzol exprésalle a Pardo (02/07/1926) a imposibilidade de crear ese novo grupo, secreto, en Madrid:

D'acordo coa nova organización do nazonalismo galego e de que sexades os de San Tiago os seus dirixentes. Non embargantes, hoxe en Madrid se non pode orgaizar un grupo segredo por duas razós: por ter desfeito a orgaización que tiñamos e hacharse na Terra os rapaces con quenes poderíase contar. Pro conmigo podedes contar dende logo e pra todo.

Esta nova concepción dun nacionalismo clandestino fai que acuñemos este último momento como intento de grupos secretos

${ }^{13}$ Penzol na carta a X. Pardo do 02/07/1926 cita: "falla de aitividade do grupo d'Ourense e da sua autuación nazonalista, sobre todo despois do que sucedeu coa «Triple Alianza» pois apareceron no Noroeste da Cruña uns xuicios de Risco que nos tiñan molestado moito, ademais de non haber mandado representante, nin dado conta a ninguén da sua aititude no dito asunto". 
("independencista" e "segredo"), porque así se deduce do epistolario de Penzol (a Filgueira Valverde), de Xavier Pardo e do compañeiro madrigalego Ángel Romero Cerdeiriña. Este escríbelle ao amigo Penzol o 13/06/1926 "Pardo faloume do grupo segredo, que está rematando a sua orgaización de tipo masónico, e prometeume poñerse axiña en relación con vosco". Un ano antes (17/11/1925) o mesmo Cerdeiriña lle enviara noticias sobre a posibilidade de formar parte do altamente secreto A. S. L. G. (Apostolado Social e Litúrxico na eirexa Galega).

Demasiado secretismo para que os galegos de Madrid puidesen intervir na metrópole galega, polo que -como veremos no seguinte apartado dedicado á actividade- se van vincular co estudantado.

\section{REXISTROS PÚBLICOS E OCULTOS}

Os grupos subalternos, como son os galegos en Madrid, teñen capacidade para crear, a partir da súa propia experiencia de marxinación e subordinación, rexistros ocultos ${ }^{14}$ nos que toma corpo a crítica do poder, ao lado dos rexistros públicos. Velaquí a explicación do último concepto segundo González-Millán (2000: 142):

O concepto de rexistro oculto, como manifestación da experiencia da subalternidade, recolle as formas discursivas (expresións, declaracións, xestos ou prácticas) que se lle ocultan ós poderes dominantes e, por estar dirixidas a outros receptores, sofren a impronta do poder de forma distinta a como o fan os rexistros públicos.
Os rexistros públicos e ocultos que imos mostrar a partir do estudo do arquivo de Fermín Penzol dependerán de cada momento: dende a galeguización dos pés nos cadros de Castelao ata unha cuestión clave como foi a irlandesa.

En canto ao primeiro, rexistro oculto, desenvolveuse durante a exposición de Castelao na Casa de Galicia en Madrid. Segundo se deduce do epistolario entre Penzol e Casas, a visita dun cargo gobernativo motivou a tradución dos pés da obra artística ao castelán ${ }^{15}$, con todo, estes aparecían na lingua orixinaria, a galega. Casas escríbelle a Penzol o 01/05/1920: "Estamos entusiasmados c'o papeliño que di vosté aparece posto todol-os dias no dibuxo de Castelao".

Sobre o segundo rexistro, tivo unha parte pública e outra oculta. Así, en xuño ${ }^{16}$ de 1921 a Irmandade Céltiga envíalle unha carta á Embaixada Británica en Madrid co seguinte contido:

Habiendo acordado el Partido Nacionalista Gallego, cuyo idearium profesamos, en su última asamblea recientemente celebrada en la ciudad de Vigo, protestar contra el hecho de impedir al pueblo irlandés la libre expresion de su voluntad nacional y habiendo sido comisionado, por el directorio de dicho partido, la delegación en Madrid de las "Irmandades da Fala na Galiza" a la cual pertenecemos para entregar a S. Ex ${ }^{a}$ el documento de protesta, deseariamos a este fin nos indicase la forma, dia y hora más oportuna de llebarlo [sic] a cabo.

Segundo se indica na carta, a Irmandade Céltiga en Madrid foi comisionada polo

\footnotetext{
${ }^{14}$ Aínda que Xoán González-Millán (2000) fala de "rexistros públicos e ocultos”, James C. Scott (2003: 19-20) prefire denominalos "discursos públicos e ocultos": "Cada grupo subordinado produce, a partir de su sufrimiento, un discurso oculto que representa una crítica del poder a espaldas del dominador. El poderoso, por su lado, también elabora un discurso oculto donde se articulan las prácticas y las exigencias de su poder que no se pueden expresar abiertamente. Comparando el discurso oculto de los débiles con el de los poderosos, y ambos con el discurso público de las relaciones de poder, accedemos a una manera fundamentalmente distinta de entender la resistencia ante el poder". Parécenos máis rica a terminoloxía de J. Scott e a de X. González-Millán que a empregada polo investigador francés M. de Certeau (2000) ao distinguir entre "estratexias" e "tácticas" como artes de facer dos consumidores ou dominados.

15 Beramendi (2007: 667) fala de censura nos pés dos debuxos.

${ }^{16}$ Beramendi indica que en maio se entrega a protesta e en xuño outra directamente ao premier Lloyd George.
} 
directorio do Partido Nacionalista Galego e as Irmandades da Fala (Penzol fora convocado para a III Asemblea Nazonalista Galega en Vigo o 31/03/1921) para presentar a protesta.

Quizais o pouco éxito desa carta da que se laian dende Galicia e dende Madrid (a embaixada resposta que o intermediario protocolario é a embaixada española en Londres) provoca novos rexistros, algúns públicos e outros ocultos. Entre os segundos están as indicacións, bastante subversivas de V. Risco, e das que descoñecemos o rumbo final. Nunha carta de Modesto P. Piñeiro (28/06/1921) exponse:

Acordamos: $1^{\circ}$ Dirixirse ô Repersentante da Repúbrica Rusa dos Soviets en Londres ou ôs Estados Unidos pra que nos persente a protesta o Governo Ingrês, porque o portugués non convén, nin ôs portugueses, que se non atreverían, nin a nós, que parecería qu'iñamos a iles por necesidade. $2^{\circ}$, Qu'a Irmandade de Madrí débese poñer en comunicazón estreita y-ofrecel-a sua axuda âs xentes do Boletín Irlandés que se pubrica en Madrí e percurase que n-ise Boletín se xalee iso de non ser ademitida a protesta, pubricando o testo en francés e galego, ademais dos comentarios.

Decir somentes que foi rechazado, iso convén eisplotalo bén sen decir como foi a cousa porque quitarialle importáncea ô millor. Decir que foi rechazado, non ademitido, por que teñen medo e vos do Direito e de Razón etc... sabes? Unha cousa esí.

Eiqui imos faguer campaña co iso e xa vos tendrei o corrente do que axa. Imos tamén esquirbir â Cruña y-a Vigo, Baiona e Pontevedra que son da nósa xurisdición. Iso é todo o que hai sobor do asunto.

Entre os rexistros públicos relacionados coa cuestión irlandesa, pénsase nunha carta de R. Villar Ponte (como director de El Correo Gallego) ${ }^{17}$ á legación do "pobo irmán" en Madrid para poñerse á disposición dos persoeiros irlandeses en España (e así o manifesta este nunha carta do 04/10/1921). No mesmo sentido debe estar a preocupación por conseguir o enderezo do Boletín Irlandés e a insistencia de
V. Casas dende Galicia para que os madrigalegos visiten o Comité Irlandés de Madrid (carta do 24/08/1921) e informen "en debida forma do noso movimento, de quenes o compoñen, das nosas arelas e de todo o que con él se relacione. Tambén convén lle digades que [se] poden contar connosco pra todo o que percisen". Dunha epístola do 29/09/1921 deducimos que esa visita se produciu e, por unha frase de X. Peña (carta do 14/12/1921), sabemos que houbo un encontro coa delegada de Irlanda (probablemente a señora O'Brien, segundo unha misiva do ano seguinte).

Outros rexistros que deducimos do epistolario terían menor relevancia como actividade grupal ${ }^{18}$ dos madrigalegos, pero maior repercusión na metrópole galega: creación da revista para a infancia galega As Roladas. Folla dos rapaciños galegos, colaboración con A Nosa Terra, busca de publicidade, cooperación en exposicións de pintura, firma ou redacción dunha carta a Murguía (cuxo contido descoñecemos), preocupación pola lingua da/ na universidade galega... De entre as citadas, queremos resaltar a difusión e propaganda de A Nosa Terra, pois Penzol, a petición de V. Casas, "fixo suscritores entre os seus coñecidos e, sobre todo, dedicouse a cobrar as suscripcións que o boletín tiña en Madrid e xirar puntualmente a Coruña a recaudación correspondente" (Piñeiro 1981b: 26).

A axuda á publicación periódica $A$ Nosa Terra será prohibida pola Irmandade Nazonalista Galega durante a seguinte etapa (como Delegación da ING). A partir de entón, os rexistros públicos serán máis ben individuais: colaboración no boletín Rexurdimento e busca de publicidade para Nós. Como rexistro oculto, neste momento impera unha vontade de "rebentar" A Nosa Terra expresada desta maneira tan crúa por Modesto P. Piñeiro (14/10/1922):

Supoño xa no teu poder unha do xefe falando de varios asuntos e antr'eles o de Rexurdimento que é unha cousa de moita importancia.

\footnotetext{
${ }^{17}$ Debeuse contactar con máis publicacións periódicas, caso de Noroeste.

${ }^{18}$ Labor de R. Cabanillas en colaboración con Penzol e Cortón (Rei 2009: 250-254).
} 
En vista do que pasa cos da Cruña estamos dispostos a [reventalos] en todo o que se poida e pra escomenzare imos ver si conquerimos sustituir A Nosa Terra pol-o de Betanzos ${ }^{19}$ xa que é o mais doado de faguer.

Precura conquerir baixar e darvos todos (incruíndome a min) na A Nosa Terra e suscribirmonos ô Rexurdimento axudandóo ademais en todo o que se poida, inda que haxa que faguer un esforzo (...).

(...) hay que faguer d'iste xornal o órgao da ING. Coma $A$ Nosa Terra viña sendo e quere sêlo da I. da F. e moito millor feito.

Eiquí estamos dispostos a todo como veríades polas cartas do Vicente de xeito que dos de Betanzos depende o demais.

Diráselle isto a Castelao, Quintanilla, etc... (...) Aparte dísto, temos que precurar matar a outra pro cal debemos de faguerlle todal-as baixas que se poda. (...) A colaboración xa está prohibida ôs irmáns da I. N. G. e circularánse as ordes (...) Imos ver quen ten mais forza e si se poidera acabar co-iles millor. Á Causa lle compria que os esmagáramos e imos poñernos a elo (...).

Que esa vontade se levou á práctica desvélao a interrupción da correspondencia entre $\mathrm{F}$. Penzol e V. Casas o 25/07/1922. Casas acéptao nos seguintes termos "Reconozo as razós que me espós para te non encarregar de $A$ Nosa Terra e xa procurarei te non molestar en nada que a ela refirase".

Nos anos posteriores, os labores dos madrigalegos da Mocedade Céltiga serán semellantes. Podemos citar:

- a colaboración con revistas e con coleccións (Libredon) na que os madrigalegos se ocuparon "como fixemos con Celtiga e Nos, de todo o concernente ô espallamento, propaganda e venda de dita revista, cumprindo co noso deber" (Grupo Nazonalista de Madrid a X. Pardo 1924-26);

- a protesta diante do coro Ruada (rexistro oculto explicado nunha carta de Penzol a Leuter González do 23/02/1925);
- a carta á mocidade do Seminario de Estudos Galegos e o comunicado para os nacionalistas de Ourense;

- a colaboración na homenaxe a Guimerá, proposta de Vilar Ponte recollida no xornal Galicia. Reproducimos a carta da Mocedade Céltiga a Valentín Paz Andrade, director de Galicia (05/02/1925):

A proposta de Vilar Ponte, de que a Galiza conscente s'engadera d'un geito efeitivo ao homenage que Catalunya prepara ao mestre Guimera, asenllada pol-os nazonalistas de Viveiro e recollida pol-o xornal Galicia encheunos de ledicia e fixo acougar os abancos lanceijados dos nosos corazós mozos, arestora de turdios e vedraños.

Unha lápida pr'o moimento a Guime$\mathrm{ra}$, en reciprocidade â crôa de bronce no moimento â Santa Rosalia, fainos de cote lembrar d'un sentimento de agarimo e d'irmandade.

Ei, a meirande ofrenda que podemos faguer a Catalunya. (...) Coa mesma data, giramoslle setenta e cinco Ptas. a que teñen acadado os nosos esforzos. E a primeira cantidade, e tencionamos que non seja a derradeira.

Nos últimos anos, tralo esfarelamento dos grupos constituídos e o intento de construír unha organización secreta (ou dúas, unha masónica e outra relixiosa, segundo se deduce do epistolario), Fermín Bouza Brey (carta de 1926) intenta que os madrigalegos se impliquen enviando un telegrama de protesta ao reitor de Santiago de Compostela contra a Juventud Hispano-América presidida por $\mathrm{Ci}-$ ríaco Pérez Bustamante e defendendo o Seminario de Estudos Galegos:

Dos incidentes estaredes enteirados por $E l$ Pueblo. Mais eu quero enteirarvos de que con motivos da protesta que fixeron os rapaces do Seminario de unha cousa que desprestixiaba â nosa Universidade, ditos estranxeiros fan campaña antigaleguista querendo facer vítima ao Seminario a quen compre defender así como aos nosos irmáns santiagueses e estudantes.

${ }^{19}$ Pénsese que o boletín Rexurdimento se edita en Betanzos (enclave de onde proceden moitos dos membros dos grupos madrigalegos) e nel inclúese o contacto e o enderezo da Delegación de Madrid. 
Atacan con tal motivo ao galeguismo todo. $\mathrm{O}$ telefonema será en castelán e podedes dar copia do mesmo aos xornaes de ahi, especialmente ao Socialista e mais ao Sol que protestaron, e remitilo tamén aos de Vigo. O que teña tíduos académicos que os poña.

Estamos na época de nos axuntar e todos estarmos en comunicazón pra nos defender. ¿Cando nos tocará a ofensiva?

Por outra parte, Emilio González López alude a tres ou catro actos importantes dos que non se encontra ningunha referencia no epistolario gardado na Fundación Penzol e que non se relacionan estreitamente coa metrópole galega. A descrición preparada por González López (1981: 349-350) incide na presenza do estudantado galego cuxa "actividade foi grande no movemento estudiantil madrileño, que foi o primeiro que se enfrentou coa Dictadura en defensa das libertades públicas":

O primeiro acto de transcendencia e importancia feito polos estudantes madrileños foi o que se celebrou no Paraninfo da Universidade Central para honrar os restos de Angel Ganivet ao seu paso para Granada. O rector da Universidade non permiteu que se lera no Paraninfo a carta que dende Francia enviara Miguel de Unamuno, vello amigo de Ganivet. Fermín e mais outros membros da M C [Mocedade Céltiga] estaban conmigo no Paraninfo. A carta lina eu na Estación de Atocha ante unha grande moitedume (...)

Unha das primeiras actividades dos estudantes contra a Dictadura foi espallar o xornal España con honra que publicaban en Francia Unamuno, Blasco Ibáñez e mais Eduardo Ortega y Gasset, no que se informaba de cantos atropellos e aldraxes cometía a Dictadura e as corrupcións dos seus servidores (...) E a M C de Madrid, a través dos seus membros, tiña unha grande participación na divulgación deste xornal.

Cando eu fundei en Madrid a Unión Liberal de Estudiantes en 1925, que foi o primeiro movemento estudiantil de protesta organizado, tamén participaron nel os rapaces da M C (...)

Unha das últimas actuacións colectivas da M C, na que a presencia de Fermín tivo a maior importancia, foi expresar a protesta da mocedade galega contra as delegacións dos concellos de Galicia que formaban parte da manifestación de alcaldes que argallou Primo de Rivera pouco tempo antes de cesar.

En canto á relación coa periferia americana, cómpre destacar a relación con Bos Aires e coa Habana. O epistolario mantido con Ramiro Illa Couto e Fuco Gómez dá fe do intercambio de información, opinións... dos que están necesitados uns e outros. Penzol explícalle a Pardo (02/07/1926) esta estreita colaboración "particularmente e xunto cos rapaces de Fouce viña traballando por erguer America unha orgaización independencista".

\section{ESPAZOS E CONTRAESPAZOS DE SOCIABILIDADE}

Existen refuxios ou espazos sociais libres, nos que os grupos subordinados madrigalegos cuestionan ideoloxías da orde imperante e desenvolven concepcións alternativas. Pero tamén existen espazos institucionalizados nos que non é posible a actividade disidente. Estes segundos serán coñecidos e abandonados polos mozos trala protesta máis ou menos pública (e da que nos informa o epistolario de V. Casas). É o caso do Centro galego (denominación empregada como sinónimo de Centro de Galicia e Casa de Galicia en Alcalá, 10) onde Emilio González (1981: 348) se encontra co "fato ${ }^{20}$ de rapaces galegos":

No Centro atopeime con un fato de rapaces galegos, un deles uns anos maior ca min, era Fermín Fernández Penzol, (...) que viña ser como o guiero de aquel grupo galego e galeguista, que se deu o nome de M C (...).

Centro Gallego por inspiración do seu presidente Francisco Fariña, botounos fora a todos nós (...) Saímos do Centro Gallego os estudantes e tivemos que andar como pelengríns dun café noutro.

Fronte ao espazo institucionalizado, existen espazos de cultura coma o Ateneo e créanse

${ }^{20}$ Terminoloxía empregada en épocas posteriores. 
contraespazos con máis ou menos continuidade. Se os locais propios ${ }^{21}$ non tiveron éxito, os cafés foron contraespazos habituais ou ocasionais: San Paulo, Cocodrilo, Kutz, Regio, Lyon, Gran Vía, El Gato Negro... Ben-Cho-Shei cita o Brasil na Gran Vía e Cortón (2010: 26-27) o San Paulo na mesma rúa:

Foi o café San Paulo, situado na Gran Vía madrileña, o que tivo as primicias de acoller un primeiro fato de estudantes galeguistas no desterro (...) moitas noites deambulando polas rúas de Madrid (...) camiñadas os dous sós de noite entre Gran Vía e a túa ou a miña morada.

As casas propias onde gardan os selos, a Biblioteca Nacional como espazo que se debería visitar, a Biblioteca do Museo de Pedagogía onde traballa L. Cortón (familiar de V. Viqueira) e as librerías de vello como lugares da memoria para o libro galego.

\section{CONCLUSIÓNS}

Ata aquí o noso breve achegamento aos grupos de galegos en Madrid durante os primeiros trinta anos do século XX cunha atención especial a Fermín Penzol. Ao seu redor xuntáronse outros estudantes e traballadores e "Pouco a pouco foi aumentando o grupo con novos estudantes, algúns deles parentes que xa estabamos nel" (González 1981: 348).
Aínda habería que citar, ademais do seu traballo posterior a prol do Estatuto de Autonomía e tantos outros ideais, unha "efémera agrupación de mozos galegos en Madrid, que produce un par de documentos en abril de 1930 e despois non dá máis sinais de vida" (Beramendi 2007: 551) de nome Acción Galega Radical Autonomista (AGRA). Entre os asinantes, ademais de Fermín Penzol, Jesús Bal y Gay, Luís Bouza Brey, Ramón Martínez López, José Ramón y Fernández Oxea, Carlos Maside, os irmáns Fernández López e outros.

Nós quixemos centrarnos na figura de Fermín Penzol e o límite de espazo confirma a amplitude da obra dun home que transformou o seu "sentimento de frustración producido pola ausencia forzada de Galicia (...) en sentimento trascendente ao servicio dunha Galicia asumida conscientemente como ideal polo que loitar" (Piñeiro 1981a: 281). Rematamos cunhas palabras de R. Piñeiro (1981a: 283):

En todo o tempo que vai desde máis ou menos do 18 ao 26, houbo en Madrid unha actividade galeguista que se inicia e desenvolve arredor de Fermín Penzol. El foi o que a iniciou e el o que, despóis de disolto o grupo, aínda continuou tratando de animar, desde Madrid, as iniciativas nacionalistas xurdidas en Galicia ou en América e, ao mesmo tempo, percurando enlazalas entre sí.

\section{REFERENCIAS BIBLIOGRÁFICAS}

AcuÑA, Ana (2009): Facer literatura galega en Madrid (1950-2000). Tese de Doutoramento. Santiago de Compostela: Universidade. (2014): Conciencia política e literatura galega en Madrid (1950-2000). Vigo: Xerais.

Alonso Montero, Xesús (1981): “O meu Fermín, o noso Penzol, o "Penzol” de todos", Grial. Revista galega de cultura 73, pp. 345-347.

BerAmend, Justo (2007): De provincia a nación. Historia do galeguismo político. Vigo: Xerais.

Borobó [García Domínguez, Raimundo] (2000): “O exemplo de Evaristo Correa Calderón”, $A$ Nosa Terra 950, p. 27.

Certeau, Michel de (2000): A invención de lo cotidiano 1. Artes de hacer. México: Universidad Iberoamericana.

\footnotetext{
${ }^{21}$ Segundo se deduce dunha carta de R. Cabanillas a R. Villar Ponte (Rei 2009: 255) parece que houbo un intento de posuír un local propio.
} 
González LóPez, Emilio (1981): "Fermín Penzol e a «Mocidade Céltiga»”, Grial. Revista galega de cultura 73, pp. 348-350.

- (1987): Memorias de un estudiante liberal (1903: 1931). Sada: Ediciós do Castro.

GonzÁlez-Millán, Xoán (2000): Resistencia cultural e diferencia histórica. A experiencia da subalternidade. Santiago de Compostela: Sotelo Blanco.

Martínez, Xurxo (2007): Fuco Gómez. AGER: Pontevedra.

- (2013): “Fermín Penzol e a Mocedade Céltiga”, A Trabe de Ouro 95, pp. 379-396.

PiñeIRO, Ramón (1981a): “A personalidade política de Fermín Penzol”, Grial. Revista galega de cultura 73, pp. 283-288.

(1981b): "Fermín Penzol deixounos o seu exemplo", Man Común 9, p. 26.

ReI, Luís (2009): Ramón Cabanillas. Crónica de desterros e saudades. Vigo: Galaxia.

Scotт, James (2003): Los dominados y el arte de la resistencia. Tafalla (Nafarroa): Txalaparta.

Villares, Ramón (1998): A Historia. Vigo: Galaxia.

VV.AA. (2010): Fermín Penzol. Unha obra para un país. Vigo: Galaxia. 